\title{
Growing Up Amid Ethno-Political Conflict: Aggression and Emotional Desensitization Promote Hostility to Ethnic Outgroups
}

\author{
Erika Y. Niwa \\ Brooklyn College, City University of New York \\ Eric Dubow \\ Bowling Green State University and The University of \\ Michigan \\ Khalil Shikaki \\ Palestinian Center for Policy and Survey Research
}

\author{
Paul Boxer \\ Rutgers University and The University of Michigan
}

\author{
L. R. Huesmann \\ The University of Michigan
}

Simha Landau

Institute of Criminology Hebrew University of Jerusalem and Yezreel Valley Academic College

\author{
Shira D. Gvirsman \\ Department of Communication Tel Aviv University
}

\begin{abstract}
Ethno-political violence impacts thousands of youth and is associated with numerous negative outcomes. Yet little research examines adaptation to ethno-political violence over time or across multiple outcomes simultaneously. This study examines longitudinal patterns of aggressive behavior and emotional distress as they cooccur among Palestinian $(n=600)$ youth exposed to ethno-political violence over 3 years in three age cohorts (starting ages: 8, 11, and 14). Findings indicate distinct profiles of aggressive behavior and emotional distress, and unique joint patterns. Furthermore, youth among key joint profiles (e.g., high aggression-emotional desensitization) are more likely to endorse normative beliefs about aggression toward ethnic outgroups. This study offers a dynamic perspective on emotional and behavioral adaptation to ethno-political violence and the implications of those processes.
\end{abstract}

Ethno-political violence is a daily reality for nearly one billion war-affected children worldwide (UNICEF, 2008). More individuals die in today's ethnopolitical conflicts compared to those in the past 200 years and up to $90 \%$ of those victims are civilians (UNICEF, 2008). Although some studies have examined youths' adjustment to ethno-political violence (see the 1996 special issue of Child Development, Vol. 67, Issue 1), this topic has still received scant empirical attention, particularly when compared to studies of exposure to violence in other key contexts (e.g., neighborhoods, homes, schools). In the 20 years since that special issue, little has changed and the situation seems even worse. This

This research was supported by a grant from the National Institute of Child Health and Human Development (Grant R01 HD047814 L.R. Huesmann, PI).

Correspondence concerning this article should be addressed to Erika Y. Niwa, Department of Psychology, Brooklyn College, Brooklyn, NY 11210. Electronic mail may be sent to eyniwa@brooklyn.cuny.edu. is certainly true in Israel and Palestine, where at least 8,829 people were killed between the beginning of the second Intifada in September 2000 and November of 2014. Approximately three-quarters of those killed were Palestinians, of whom $19 \%$ were children or adolescents (B'Tselem: Israeli Information Center for Human Rights in the Occupied Territories, 2014).

Extant research routinely has found that exposure to ethno-political violence is associated with a range of negative psychological and behavioral outcomes (e.g., Betancourt, McBain, \& Brennan, 2014; Boxer et al., 2013; Cummings et al., 2010; Dubow et al., 2012; Merrilees, Taylor, Goeke-Morey, Shirlow, \& Cummings, 2014; UNICEF, 2008). Contexts of intractable ethno-political violence, such as in the

(C) 2016 The Authors

Child Development (c) 2016 Society for Research in Child Development, Inc. All rights reserved. 0009-3920/2016/8705-0012

DOI: $10.1111 /$ cdev.12599 
Middle East, often act to heighten distinctions between one's ethnic group and the "other" (BarTal, 2004; Brenick et al., 2007, 2010; Niwa et al., 2014), in turn shaping youths' emotional, behavioral, and social-cognitive development. Although literature on this topic has been increasing (e.g., Barber, 2009; Boxer et al., 2013; Brenick et al., 2007, 2010), the limited extant research typically has focused on outcomes within one developmental domain (e.g., internalizing symptoms) without examining other developmental processes as they occur simultaneously among youth chronically exposed to ethno-political violence. This is surprising given that previous research has found that high levels of violence exposure might lead to varying pathways of adaptation or maladaptation (Boxer \& Sloan-Power, 2013; Ng-Mak, Salziner, Feldman, \& Stueve, 2002; Wainryb, 2011).

\section{The Impact of Violence on Adjustment}

Violence is pervasive, found in every setting of social experience, and can have comprehensive and devastating effects on development (e.g., Boxer \& Sloan-Power, 2013; Boxer et al., 2013; Bronfenbrenner, 1979; Finkelhor, Turner, Ormrod, \& Hamby, 2010). Research across settings has illustrated consistently that exposure to violence is linked to psychological and behavioral problems including depression, anxiety, posttraumatic stress (PTS) symptoms, substance abuse, aggressive and antisocial behavior, and academic difficulties (Boxer \& Sloan-Power, 2013; Lynch, 2003).

The limited extant studies focusing specifically on ethno-political violence have found similar associations with PTS symptoms, emotional problems, anxiety, and depression (e.g., Barber, 2009; Betancourt et al., 2010; Cummings et al., 2010; Dubow et al., 2010; Merrilees et al., 2014). The majority of this literature has focused on PTS, framing children and youth exposed to ethno-political violence as victims of trauma without necessarily attending to their agency or the vast variation in youths' responses to such exposure (Wainryb, 2011; Wainryb \& Pasupathi, 2010). Beyond the predominant focus on emotional or internalizing symptoms, exposure to ethno-political violence also has been linked to increased aggressive behavior (e.g., Barber, 2009; Boxer et al., 2013; Dubow et al., 2010). Betancourt et al. (2014) also found variation in patterns of aggression over time among war-affected Sierra Leonean youth. The majority of youth reported low and stable aggressive behavior, whereas others displayed increasing, decreasing, or sustained heightened aggressive behavior. Such studies, however, principally focus on single outcomes in isolation (e.g., Cummings et al., 2010; Dubow, Huesmann, \& Boxer, 2009), despite repeated calls to examine multiple potential outcomes simultaneously (e.g., Wainryb, 2011; Wainryb \& Pasupathi, 2010).

\section{Emotional and Behavioral Pathways to Adjustment}

The extant literature on youth exposure to violence has typically examined processes of emotional and behavioral development as separate, but simultaneous, processes. This is surprising given that a host of research has consistently illustrated a correlation between internalizing and externalizing behaviors. Despite this fact, researchers only recently have begun to consider more directly how exposure to violence impacts youths' emotional and behavioral outcomes in concert. One model is a stress or distress pathway in which experiences with violence promote negative coping and disrupt healthy emotional regulatory styles to produce emotional distress, externalizing difficulties, internalizing symptoms, and PTS (Boxer \& Sloan-Power, 2013). A second model is a normalization or socialization pathway in which experiences with violence promote a cognitive orientation dominated by a hostile interpersonal orientation, acceptance or approval of violence, and general moral disengagement (Boxer \& Sloan-Power, 2013; Huesmann \& Guerra, 1997).

Alternate pathways integrating behavioral and emotional outcomes also are possible and pose a challenge as to what constitutes adjustment or maladjustment (e.g., Wainryb, 2011). For example, "pathologic adaptation" describes youth exposed to violence who display high levels of antisocial behavior coupled with little or decreasing emotional distress (Ng-Mak et al., 2002). Such reactions might be facilitated by gradual emotional desensitization to and normalization of violence, particularly in an environment overshadowed by ongoing ethno-political violence. This desensitization might in fact be adaptive by dampening emotional distress despite persistent violence. Although this study focuses on the intersection of emotional and behavioral outcomes, other potential pathways include those in which youth display resilience and engage in youth civic engagement, such as political resistance, to promote peace. Regardless of the myriad possible pathways, examining developmental domains in isolation cannot adequately capture the complexity of youths' responses to violence over 
time. This study examines these multiple pathways by focusing on the intersection of unique longitudinal patterns of behavioral and emotional adjustment, as well as how such joint adjustment patterns shape normative beliefs about aggression (NOBAGS) toward the outgroup.

\section{The Case of Ethno-Political Violence}

Theory and research have underscored the fact that children can be exposed to violence across multiple contexts such as in the family or neighborhood (e.g., Boxer \& Sloan-Power, 2013; Finkelhor et al., 2010). For children growing up in some regions of the world, such as the Middle East, this social ecology also includes the broader politicalcultural environment, in which deeply seated ethnic and sociopolitical conflicts have insidious effects on children's everyday lives (e.g., Brenick et al., 2010; Dubow et al., 2009). Unlike many other forms of violence, ethno-political violence is an extension of deeper ethnic and political rifts among specific groups based on a history of conflict between them (Bar-Tal, 2004; Brenick et al., 2010; Dubow et al., 2009). In such contexts, negative and dehumanizing stereotypes of the "other" not only act as the outcomes of animosity between the involved groups, but also act to perpetuate the conflict by creating a cognitive basis for the hostility and mistrust between groups (Brenick et al., 2010; Niwa et al., 2014). This deep-seated distrust of the "other" (Schwartz \& Struch, 1989) is particularly heightened in intractable ethno-political conflict because clear lines are drawn between the ingroup and the "other," and the conflict itself is sanctioned by political leaders (Bar-Tal, 2004; Niwa et al., 2014). In fact, such distrust is even found to emerge at an early age among Palestinian and Israeli children (Brenick et al., 2010). Ethno-political violence exists both in the microsystems of youths' lives and in the larger macrosystem-including the beliefs and ideologies in a given culture -in which they are embedded (Bronfenbrenner, 1979). This is particularly important in contexts of violence, political exclusion, and oppression. In the case of the Middle East, Israeli Jews and Palestinians represent the clear "other" to one another. Furthermore, exposure to protracted ethno-political violence appears to be associated with higher levels of aggressive behavior (Boxer et al., 2013) and might also be linked to emotional desensitization over time. Emotional desensitization refers to the gradual process in which individuals show less emotional distress over time, despite being exposed to violence. Both aggression and desensitization have also been found to be factors that can impact social-cognitive beliefs about ethnic outgroups (e.g., Niwa et al., 2014).

\section{The Impact of Emotional and Behavioral Factors on Social Cognitions About the "Other"}

We know little about the longitudinal profiles of aggressive behavior and emotional distress as they occur simultaneously and their implications for social cognitions about the "other," which might be heightened in contexts of ethno-political conflict (Brenick et al., 2010; Niwa et al., 2014; Wainryb, 2011). The expansive literature on aggression emphasizes the role of normative beliefs as one set of social cognitions that supports the use of aggression (see Huesmann, 1998). Children develop NOBAGS -self-regulating beliefs about the acceptability of aggression as a response to provocation or a general behavioral style (Huesmann \& Guerra, 1997)primarily through socialization experiences over time (e.g., Guerra, Huesmann, \& Spindler 2003). Normative beliefs might be influenced by personal and environmental factors, but are ultimately social cognitions learned over time as youth navigate their social contexts.

Although much research has focused on NOBAGS generally, little research has examined these beliefs with regard to specific outgroups. This is a meaningful gap given that negative perceptions of outgroups are particularly intensified in interethnic conflict where there is exposure to rampant aggression and violence perpetrated against and by ethnic outgroups coupled with extremely negative characteristics that are attributed to those outgroups (e.g., Bar-Tal, 2004; Niwa et al., 2014). Growing up in contexts of ethno-political violence has broad implications not only for emotional and behavioral pathways but also for how children make moral decisions, develop stereotypes, and exclude the "other" (Niwa et al., 2014; Posada \& Wainryb, 2008). This is particularly important given that how children and youth adapt to a context replete with ethno-political conflict and violence has important implications for normative beliefs endorsing hostility toward ethnic outgroups. The few exceptions illustrate that NOBAGS toward ethnic outgroups are increased in particular in contexts of intergroup conflict (Amjad \& Wood, 2009; Schechtman \& Basheer, 2005). For example, Schechtman and Basheer (2005) found that Israeli Arab children held normative beliefs endorsing greater aggression toward Jewish children as opposed to aggression toward 
Arab children. Furthermore, in research examining Colombian children (ages 6-12) growing up in a context of prolonged armed conflict and displacement, Ardila-Rey, Killen, and Brenick (2009) found that children exposed to extreme violence were more likely to judge denying resources or inflicting harm as more legitimate when provoked by others. Such findings illustrate the pivotal role of NOBAGS both generally and toward outgroups in contexts of war and intergroup conflict. No research to date has examined whether ethno-political violence is experienced via response patterns across personalbehavioral domains (aggressive behavior and emotional distress) and across time, subsequently shaping NOBAGS toward the "other."

\section{The Present Study}

This study examines joint processes of aggressive behavior and emotional distress simultaneously over time among Palestinian youth and their subsequent influence on NOBAGS toward Israel Jews. Specifically, we examine the varying developmental patterns that youth display over time in aggressive behavior and emotional distress both separately and conjointly. Previous analyses of these data have shown that exposure to ethno-political violence uniquely contributes to higher levels of PTS symptoms and aggressive behavior, over and above the contributions of violence in other contexts (e.g., family, school, community; Boxer et al., 2013; Dubow et al., 2010, 2012). Here, we focus on unique longitudinal patterns of both aggressive behavior and emotional distress over time, how they co-occur, and how they impact NOBAGS toward Israeli Jews among Palestinian youth $(N=600)$ growing up in a context of persistent ethno-political violence.

Given that previous research and theory indicate that not all youth follow similar developmental patterns, particularly in response to exposure to violence, we ask the following questions: (a) Are there distinct trajectories over time in aggressive behavior and emotional distress? Based on previous research (Betancourt et al., 2014), we expect distinct profiles for aggressive behavior with, at minimum, two stable profiles (low and high). In addition, we expect distinct varying profiles of emotional distress, with the majority of youth displaying moderate emotional distress due to the stressful nature of ethno-political violence and another subgroup displaying emotional desensitization (Ng-Mak et al., 2002). (b) How does membership overlap in these distinct trajectories of aggressive behavior and emotional distress? Of particular interest is joint membership in trajectories that reflect negative behavioral outcomes (high aggressive behavior) coupled with emotional desensitization (gradual decrease in emotional distress), as they represent a potentially maladaptive joint process. (c) Finally, is joint membership in trajectory groups who display particularly worrisome joint patterns of behavioral and emotional distress associated with endorsement of NOBAGS toward the "other" (in this case, Israeli Jews)? Specifically, we explore whether it might be that youth who display emotional desensitization coupled with high levels of aggressive behavior represent a marginalized group who might harbor the greatest hostility toward the "other."

\section{Method}

\section{Sampling Procedures}

Data are from three waves of a larger longitudinal study examining the effects of exposure to violence among three age cohorts of Palestinian and Israeli youth $(8,11$, and 14 years at Wave 1$)$. This study focuses only on Palestinian $(N=600)$ because they reported the highest levels of exposure to ethno-political violence in our sample (see Boxer et al., 2013). At Wave 1, the Palestinian sample included 200 eight-year-olds (101 girls, 99 boys), 200 eleven-year-olds (100 girls, 100 boys), and 200 fourteen-year-olds (100 girls, 100 boys), along with one of their parents (98\% mothers). Residential areas $(64 \%=$ West Bank; 36\% $=$ Gaza Strip) were sampled proportionally to achieve a representative sample of the general Palestinian population with the use of census maps (for a more in-depth description of our sampling procedure, see Boxer et al., 2013). Sixty-one families declined to be part of the sample (rejection rate $=10 \%$ ). Staff from the Palestinian Center for Policy and Survey Research conducted the sampling and interviews.

Nearly all (599 of 600) parents reported being Muslim, and 99\% were married. One third of parents reported having at least a high school degree, and $47 \%$ reported their incomes as below the Palestinian average $(33 \%=$ average, $20 \%=$ above average). On average, parents reported $4.89(S D=1.86)$ children in the home. These statistics are representative of the general Palestinian population (Palestinian Central Bureau of Statistics, 2008). At Waves 2 and 3, 590 and 572 Palestinian children and their parents were reinterviewed (resampling rates of $98 \%$ and $95 \%$, respectively). Wave 3 was briefly 
interrupted by the 2009 incursion of Israeli troops into Gaza (Operation Cast Lead), but the disruption in interviewing only lasted 2 weeks. $T$ tests of Wave 1 study variables revealed that attrition was not associated with any key variables.

\section{Procedures}

This research protocol was approved by the institutional review boards of the University of Michigan (Behavioral Sciences) and Hebrew University of Jerusalem. Potential participants were told that the study concerned the effects of ethno-political conflict on children and families, assessments would take approximately $1 \mathrm{hr}$, and one parent and one child would be asked to participate. Consent forms did not make explicit the fact that the study was being conducted simultaneously in Israel and Palestine, as the highly contentious and ongoing conflict between these two groups could have predisposed participants to be more likely to reject participation in the study. Written parent consent and child assent were obtained, including a description of the study and an explanation that participation was voluntary and confidential. Families were compensated $\$ 25$ for the $1 \mathrm{hr}$ interview. Parent and child interviews were conducted separately and privately in families' homes. Interviewers read surveys to respondents, who indicated answers that were then recorded. The study was conducted in three yearly waves of assessment. Wave 1 was conducted from May 2007 through September 2007, Wave 2 was conducted from May 2008 through September 2008, and Wave 3 was conducted from May 2009 through August 2009.

\section{Measures}

Demographic Information. Parents and youth responded to standard questions to assess demographic characteristics (e.g., age, gender, ethnic group, national group, region, parents' average educational level). The key demographic variables of age, gender, parents' average educational level, and region (West Bank vs. Gaza Strip) were included in our analyses.

Emotional Distress. Emotional distress was assessed using the emotional symptoms five-item subscale from the Strengths and Difficulties Questionnaire (Goodman, Ford, Simmons, Gatward, \& Meltzer, 2000; $\alpha=.56)$ that reports on children's general emotional symptoms. Parent reports were used for 8-year-olds, whereas combined parentand self-reports were used for 11- and 14-year-olds.
Participants provided ratings of emotional distress on questions (e.g., "I am often unhappy, sad, or tearful") on a scale from $0=$ not true to $2=$ very true. Goodman (2001) has reported robust scale structure and this scale has been used across a range of samples. In addition, Goodman (2001) has also similar internal reliability and good validity via significant links to other established scales as well as clinical diagnoses. In this article, emotional distress will refer to this overall measure of emotional symptoms, whereas terms such as "emotional desensitization" will refer to specific pathways or patterns of emotional distress over time.

Aggressive Behavior. Children's aggressive behavior was assessed using a composite of three childand parent-reported measures (see Dubow et al., 2010). These three measures were used to assess children's aggressive behavior and were combined to create a composite score (for further detail, see Dubow et al., 2010). First, a modified version of the Peer Nomination of Aggression Inventory (Eron, Walder, \& Lefkowitz, 1971) was administered as a self-report measure for children. The 10 items $(\alpha=.80)$ are based on the original peer-rated index of general aggressive behavior. Children provided ratings on a 4-point scale ranging from $0=$ never to $3=$ almost always on items measuring verbal aggression (e.g., "How often do you say mean things?"), physical aggression (e.g., "How often do you push or shove other people = kids?"), indirect aggression (e.g., "How often do you make up stories and lies to get others into trouble?"), and acquisitive aggression (e.g., "How often do you take others' things without asking?").Second, youth were administered the four-item $(\alpha=.57)$ Severe Physical Aggression scale (Huesmann, Eron, Lefkowitz, \& Walder, 1984; Lefkowitz, Eron, Walder, \& Huesmann, 1977). Respondents indicated how often in the last year they had engaged in each behavior in the past year along a 4-point scale from 0 (never) to 3 (5 or more times). Sample items were "How often have you punched or beaten someone?" and "How often have you choked someone?" Finally, parents reported on their children's aggression using the 20-item aggression scale $(\alpha=.89)$ from the Child Behavior Checklist (Achenbach \& Edelbrock, 1983). Parents rated the extent to which their child displayed each problem within the past 6 months (e.g., "argues a lot," "threatens people," "gets in many fights") on a 3-point scale (i.e., $0=$ not true (as far as you know), 1 = somewhat or sometimes true, and 2 = very true or often true). As all three measures were positively skewed, log transformations were applied to all of them. Finally, latent variable 
modeling was used to estimate a score for aggressive behavior integrating information across selfand parent reports (see Dubow et al., 2010, for further detail). Using the AMOS 20 (IBM SPSS, Chicago, IL) program, we applied latent variable modeling to estimate a score for aggressive behavior by integrating information across self- and parent reports. The AMOS program estimates the measurement parameters that best represent the correlations among the variables making up the composite $(d f=0)$. The program subsequently generates via regression imputation new variables for the latent factor scores. Because we found the model with the three aggression indices to be metrically invariant across the ethnic groups (comparative fit index $=.99$, root mean square error of approximation $=.025$ ), we factor weighted the indices to create a composite aggression score. The computed composite was based on the following factor score weights: $.004 \times$ parent-reported child behavior checklist-aggression $+.037 \times$ self-reported general aggression $+.075 \times$ self-reported severe physical aggression.

NOBAGS Toward the Out-Group. An adapted version of the NOBAGS (Huesmann \& Guerra, 1997) measure was used to assess children's beliefs about aggressing toward the out-group $(\alpha=.92)$. The original NOBAGS ask children to rate the extent to which certain aggressive behaviors are "okay" or "wrong." For the present study, a sevenitem measure of approval of aggressive acts that target the "outgroup" was developed. In the context of the current ethno-political conflict in this region, the ethnic outgroup for the Palestinian youth in our sample was Israeli Jews. Children were asked to indicate their approval or disapproval of aggression that targets out-group members along a 4-point scale from 1 = always wrong to 4 = always $O K$. The seven items were as follows: "In general, is it OK for Palestinians to curse at Israelis?," "If a Palestinian is angry, is it OK for them to threaten to kill Israelis?," "In general, is it OK for Palestinians to throw stones at Israelis?," "Is it usually OK for Palestinians to harm Israelis?," "Is it OK for Palestinians to insult Israelis?," "Is it OK for Palestinians to damage Israeli property?," and "Is it generally OK for Palestinians to stake Israeli property?" Higher scores reflect stronger support that aggression against the outgroup is justified.

All measures were presented with no variation between data collection waves. Measures were presented in Arabic for the Palestinian youth and original English measures were back translated for accuracy by native-speaking research teams at the two data collection sites. Our surveys also went through pilot testing with nine parent-child dyads (three from each age group) in each ethnic group from our larger study (Palestinian, Israeli Arab, Israeli Jewish). Pilot testing included asking participants to discuss items or response formatting that caused confusion. Item content and response formatting were found to be understandable across age and ethnic groups.

\section{Overview of Analyses}

Identification of the Developmental Models of Aggressive Behavior and Emotional Distress A person-oriented, semiparametric group mixture model was used to identify and validate distinct patterns of aggressive behavior and emotional distress over time using SAS Proc Traj (Jones, Nagin, \& Roeder, 2001; Nagin, 2005; Nagin \& Tremblay, 2001). The use of a person-oriented growth mixture model approach is based on the assumption that there is heterogeneity in individuals' intercepts, rates of change over time, and the direction and shape of such change (e.g., Nagin \& Tremblay, 2001; Windle \& Weisner, 2004). In comparison, variable-centered analyses (such as hierarchical linear modeling) estimate individual differences around a single growth curve, even if they are not assumed to have similar patterns over time (e.g., Windle \& Weisner, 2004). In this case, a person-centered approach untangles critical intraindividual variability over time from interindividual variability in pathways of aggressive behavior and emotional distress separately and then examines joint membership across both variables.

Modeling procedures involve estimating growth curves for each individual, and then identifying prototypic group curves based on the individual trajectories estimated for each population member. The degree to which each individual's growth curve resembles each of the prototypic group curves is estimated by posterior probabilities (ranging from 0 to 1 ); individuals are classified into the trajectory group for which they have the highest probability of membership. Thus, model outputs include the shape of each trajectory (patterns of stability and change), the estimated proportion of the population in each trajectory, and the probability that each individual belongs to each group.

The model selection process involved estimating a series of models with varying numbers of 
trajectory groups up to six groups. Decisions about the optimal number of groups, as well as their shape (constant, linear, or quadratic), were guided by the Bayesian information criterion (BIC); models with the largest BIC (indicating better model fit) were selected. Parsimony was favored when selecting competing models with comparable BIC statistics. This process was conducted separately for aggressive behavior and emotional distress.

Model parameters were estimated using full information maximum likelihood (FIML), which permits for missing values (Jones et al., 2001; Nagin, 2005). FIML is recognized as an appropriate, unbiased, and efficient method of estimating missing longitudinal data (e.g., Allison, 2001). Its use makes this analysis robust to missing data, and can accurately estimate individuals' trajectories with one or more data points (Nagin, 2005).

After conducting latent group mixture models, descriptive analyses, specifically chi-square analyses, were used to explore whether there were significant differences in trajectory group membership for both emotional distress and aggressive behavior by the key demographic characteristics of this sample (sex, age cohort, parents' average educational level, and subregion). Analyses of variance (ANOVAs) were also utilized to describe whether there were significant differences in mean levels of NOBAGS toward the outgroup based on trajectory group membership separately for emotional distress and aggressive behavior. This provides a baseline level of analysis prior to examining mean levels of NOBAGS based on joint aggression-emotional distress group membership.

Joint Membership in Trajectory Groups for Aggressive Behavior and Emotional Distress. Next, we develop joint membership trajectory groups by examining simultaneous membership in aggressive behavior and emotional distress trajectory groups. This allows us to identify youth who are both high in aggression across time points and declining in emotional distress across time points so that we can test the hypothesis that youth who display emotional desensitization coupled with high levels of aggressive behavior might harbor the greatest hostility toward the outgroup compared to their high-aggressive counterparts who do not show evidence of emotional desensitization.

Linking Patterns of Emotional Distress Among High-Aggressive Youth to NOBAGS Toward the Out-Group. Finally, we compute hierarchical linear regression analyses to explore whether joint trajectory group membership across both emotional distress and aggressive behavior predicts NOBAGS toward the outgroup, in this case Israeli Jews, after controlling for key demographic characteristics and normative beliefs at Time 1 .

\section{Results}

\section{Descriptive Analyses and Bivariate Correlations for Study Variables}

Table 1 presents the means, standard deviations, ranges, and bivariate correlations for all study variables.

\section{Identification of the Developmental Models of Aggressive Behavior and Emotional Distress}

Aggressive Behavior. The best fitting model for aggressive behavior specified three stable trajectory profiles (BIC $=-262.38)$. Parameter and group membership estimates for trajectories in the final models were all significant $(p<.001)$. The posterior probabilities of group membership for the threegroup model were also superior to those for competing models. The mean posterior probability scores for all three of the trajectory groups were high $(M=0.84-0.91)$, indicating a good fit. All three profiles were stable over time and varied only by the level of aggressive behavior. The first profile included youth who reported low and stable levels of aggressive behavior (low-stable $=49 \%$ ). The second profile represented youth who reported moderate and stable levels of aggressive behavior (moderate-stable $=41 \%$ ) and the third profile represented youth who reported high and stable levels of aggressive behavior over time (highstable $=10 \%$; see Figure 1 ).

Descriptive analyses illustrate differences in aggressive behavior trajectory group membership by our key demographic variables (region, age cohort, gender, parents' education). First, there were significant differences based on region in aggressive behavior trajectory group membership, $\chi^{2}(2,600)=46.48, p<.001$. Although youth in the low-stable aggressive behavior trajectory group were relatively equally split by region $(51 \%=$ West Bank), the majority of youth in both the moderatestable $(73 \%)$ and the high-stable $(88 \%)$ aggressive behavior trajectory groups was from the West Bank. There were also significant differences in aggressive behavior group membership based on both age cohort and gender, $\chi^{2}(4,600)=16.64, p<.01$ and $\chi^{2}(2,600)=30.25, p<.001$, respectively. The groups who displayed higher levels of aggressive behavior over time tended to contain older children. For 
Table 1

Means, Standard Deviations, and Intercorrelations Among Study Variables

\begin{tabular}{|c|c|c|c|c|c|c|c|c|c|}
\hline & $M(S D)$ & 1 & 2 & 3 & 4 & 5 & 6 & 7 & 8 \\
\hline $1 \mathrm{NBO}$ T1 & $2.92(1.01)$ & - & & & & & & & \\
\hline 2 NBO T2 & $2.98(0.97)$ & $.56^{* * *}$ & - & & & & & & \\
\hline 3 Agg T1 & $0.35(0.78)$ & $.20^{* * *}$ & $.15^{* * *}$ & - & & & & & \\
\hline 4 Agg T2 & $0.35(0.79)$ & .02 & .00 & $.64^{* * *}$ & - & & & & \\
\hline 5 Agg T3 & $0.47(0.79)$ & -.05 & .02 & $.56^{* * *}$ & $.74^{* * *}$ & - & & & \\
\hline 6 ED T1 & $0.83(0.41)$ & $-.11^{* *}$ & $.17^{* * *}$ & $.17^{* * *}$ & $.12^{* *}$ & $-.11^{* *}$ & - & & \\
\hline 7 ED T2 & $0.77(0.40)$ & $-.14^{* * *}$ & $-.13^{* *}$ & $.15^{* * *}$ & $.25^{* * *}$ & $.19^{* * * *}$ & $.53^{* * *}$ & - & \\
\hline 8 ED T3 & $0.74(0.37)$ & $-.12^{* *}$ & $-.12^{* *}$ & $.09^{*}$ & $.10^{*}$ & $.13^{* *}$ & $.51^{* * *}$ & $.50^{* * *}$ & - \\
\hline
\end{tabular}

Note. $\mathrm{NBO}=$ normative beliefs about ethnic outgroups; $\mathrm{ED}=$ emotional distress; $\mathrm{Agg}=$ aggressive behavior (mean scores for aggressive behavior are based on a composite score derived through latent variable measurement modeling of three manifest variables. Individual scores for the three measures were standardized, multiplied by factor weights observed in the measurement model, and then averaged to create the aggression composite. Mean scores for emotional distress are based on raw combined scores.). ${ }^{*} p<.05$. ${ }^{* *} p \leq .01$. $* * * p \leq .001$.
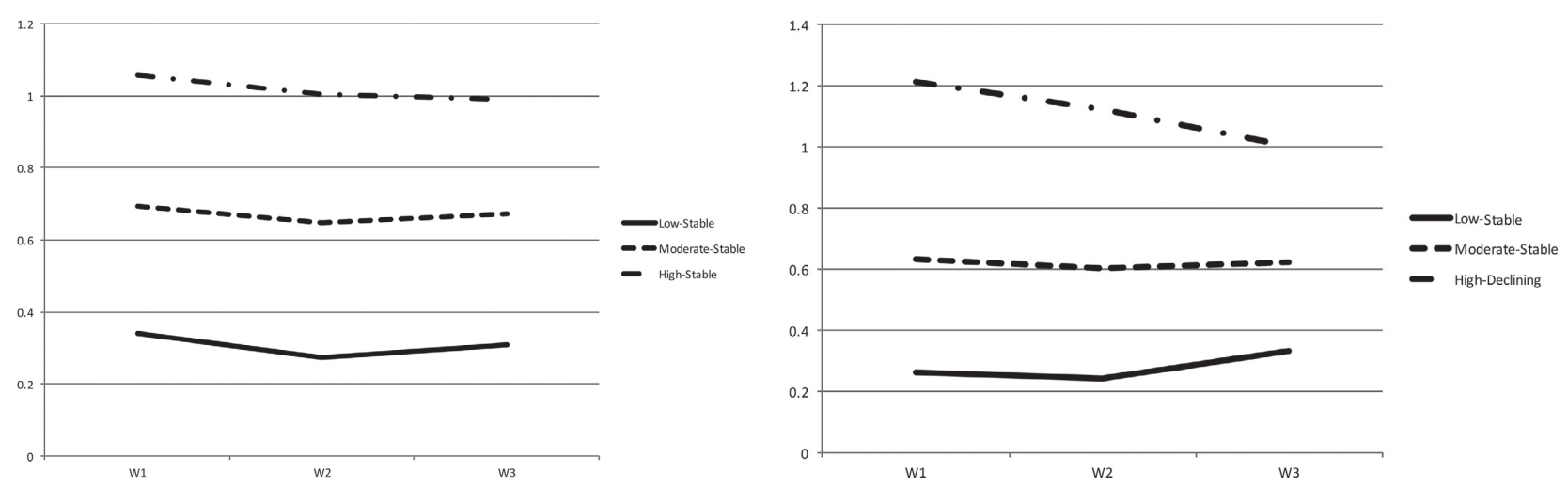

Figure 1. Trajectory profiles of aggressive behavior and emotional distress.

example, in the low-stable aggressive behavior group, $41 \%$ are 8 -year-olds at $\mathrm{T} 1,30 \%$ are 11 -yearolds at $\mathrm{T} 1$, and $29 \%$ are 14 -year-olds at $\mathrm{T} 1$, whereas in the high-stable aggressive group, $21 \%$ are 8 year-olds at $\mathrm{T} 1,36 \%$ are 11 -year-olds at $\mathrm{T} 1$, and $43 \%$ are 14 -year-olds at $\mathrm{T} 1$. With regard to gender, the more aggressive groups tended to have more males, such that the low-stable aggressive group had 59\% female, whereas the high-stable aggressive group had only $21 \%$ female. Finally, there were no significant differences in aggressive behavior group membership based on parents' average education.

Emotional Distress. The best fitting model for emotional distress specified three trajectory profiles, two stable and one linear and declining $(B I C=-771.95)$. Parameter and group membership estimates for trajectories in the final models were all significant $(p<.001)$. The posterior probabilities of group membership for the three-group model were superior to those for competing models. The mean posterior probability scores for all three of the trajectory groups $(M=0.78-0.85)$ further indicated a good fit. The first profile included youth who reported low and stable emotional distress (low-stable $=19 \%)$. The second profile represented youth with moderate and stable emotional distress (moderate-stable $=52 \%$ ). The third profile included youth who reported high and declining emotional distress over time (high-declining $=29 \%$; see Figure 1). Based on expectations that exposure to ethno-political violence would be associated with high and stable levels of emotional distress over time, we assume that the low-stable emotional distress group represents youth who display some degree of emotional disengagement, whereas the high-declining emotional distress group represents youth who display emotional desensitization. From this point forward, emotional desensitization will refer to the high-declining emotional distress trajectory group, whereas emotional disengagement will 
refer to the low-stable emotional distress trajectory group.

Descriptive analyses illustrate differences in emotional distress trajectory group membership by our key demographic variables (region, age cohort, gender, parents' education). There are no significant differences between youth in Gaza versus the West Bank with regard to emotional distress trajectory group membership. Similar to aggressive behavior, there were significant differences in emotional distress group membership based on both age and gender, $\chi^{2}(4,600)=15.04, \quad p<.01$ and $\chi^{2}(2$, $600)=10.19, p<.01$, respectively. Specifically, the low-stable emotional distress group had a higher proportion of 8 -year-olds at T1 $(48 \%)$, whereas membership in the moderate-stable and high-declining emotional distress groups were relatively equally split by age cohort. In addition, the lowstable emotional distress group had a higher proportion of men, whereas the high-declining emotional distress group had a higher population of women (low-stable $=40 \%$ female; moderatestable $=49 \%$ female; high-declining $=59 \%$ female) . Finally, there were also significant differences in emotional distress group membership based on parents' average education, $F(2,595)=9.54, p<.001$, with the low-stable emotional distress group having parents with the highest educational level, followed by the moderate-stable distress group, and finally, the high-declining distress groups were more likely to have parents with the lowest level of education.

Joint Membership in Trajectory Groups for Aggressive Behavior and Emotional Distress. As noted above, analyses revealed three stable trajectory groups of aggressive behavior (low $=48 \%$, moderate $=41 \%$, and high $=11 \%$ ) and three trajectory groups of emotional distress (lowstable $=20 \%$, moderate-stable $=50 \%$, high-declining $=30 \%$ ). Youth were then found to be in one of nine joint trajectory groups. The majority of youth were members of joint groups with moderate aggressive behavior and/or emotional distress, indicating that the majority of Palestinian youth in our sample displayed adaptation to persistent ethno-political violence by predominantly not having elevated levels of either aggressive behavior or emotional distress over time. Of particular interest, however, are youth who were members of groups who display negative behavioral adaptation and emotional desensitization or disengagement in the face of violence. In this case, we focused on examining youth who displayed high-stable aggressive behavior coupled with either low-stable (disengagement) or high-declining (desensitization) emotional distress. A number of important findings emerged from examining joint membership across these two domains. First, $11 \%$ of the full sample exhibited consistently high levels of aggressive behavior over time. Of those youth, 21\% simultaneously displayed low-stable emotional distress, whereas 39\% displayed high-declining emotional desensitization. Second, $20 \%$ of our sample reported consistently low levels of emotional distress over time, indicating potential emotional disengagement. Among this group, the majority of youth showed low-stable levels of both emotional distress and aggressive behavior (57\%), whereas $11 \%$ displayed low-stable emotional distress coupled with highstable aggressive behavior. Finally, almost one third $(30 \%)$ of participants were members of high-declining emotional desensitization groups. When examining the demographic breakdown of youth in the high-stable aggressive behavior group based on emotional distress trajectory group membership, there were no significant differences based on age cohort, region, or parents' average educational level. There were, however, significant gender differences, $\chi^{2}(2,600)=14.54, p<.001$, with boys in the high-aggressive behavior group being more likely to simultaneously be members of either the low-stable and the moderate-stable emotional distress groups.

Prior to examining whether joint membership was associated with NOBAGS toward ethnic outgroups, baseline descriptive analyses were conducted to highlight variation by trajectory group membership in NOBAGS. One-way ANOVAs were conducted to evaluate the relationship between trajectory group membership and NOBAGS toward ethnic outgroups. ANOVAs were conducted separately for aggressive behavior trajectory groups and emotional distress trajectory groups. In both sets of analyses, the independent variable was trajectory group membership, whereas the dependent variable was the mean level of NOBAGS toward the ethnic outgroup. ANOVAs revealed that there were no significant differences in mean levels of NOBAGS toward ethnic outgroups at Time 1 due to membership in emotional distress trajectory groups. However, there were significant differences in levels of normative beliefs at Time 1 based on aggressive behavior group membership, $F(2,597)=2.98$, $p=.052$. Specifically, youth who were members of the low-stable aggressive behavior group endorsed significantly lower levels of normative beliefs compared to those in the high-stable 
aggressive behavior group. At T3, there were significant differences in levels of normative beliefs based on trajectory group membership for both aggressive behavior and emotional distress, $F(2$, $568)=3.37, p<.05$ and $F(2,568)=4.69, p<.01$, respectively. Specifically, as we might expect based on mean differences at Time 1, youth in the low-stable aggressive behavior group endorsed significantly lower levels of normative beliefs compared to those in the high-stable aggressive behavior group $(p<.05)$. With regard to emotional distress, youth in the high-decreasing emotional distress group reported significantly lower normative beliefs at Wave 3 compared to those in either the low-stable or the moderate-stable emotional distress groups $(p<.05$ and $<.01$, respectively). Taken together, these descriptive findings support our focus on specific joint trajectories, especially those who display high-stable aggressive behavior and high-decreasing emotional distress.

Linking Patterns of Emotional Distress Among High-Aggressive Youth to NOBAGS Toward the Outgroup. Based on theory regarding adaptation in contexts of persistent exposure to violence (Boxer \& Sloan-Power, 2013; Luthar \& Cicchetti, 2000; NgMak et al., 2002) and our baseline analyses comparing normative beliefs based on aggressive behavior and emotional distress, we were particularly interested in examining endorsement of NOBAGS toward the outgroup (Israeli Jews) among youth who were members of groups who displayed highstable aggressive behavior profile based on their membership in emotional distress profiles (e.g., high-declining emotional distress, low-stable emotional distress). These groups were chosen as they represent negative behavioral adaptation (high aggressive behavior) and varying levels of potential emotional desensitization. Furthermore, research and theory have asserted that NOBAGS are associated with aggressive behavior (e.g., Guerra \& Huesmann, 2004; Huesmann, 1998).

Utilizing joint trajectory group membership derived from the prior analyses, hierarchical linear regression analysis was conducted to examine whether NOBAGS toward the outgroup at Time 3 varies among youth in the high-stable aggressive behavior trajectory group as a function of their emotional distress trajectory group after controlling for demographics (age cohort, gender) and normative beliefs at Time 1. The first block included key demographic variables (age cohort, sex, parents' average educational level, and region) and normative beliefs at Time 1; the second included joint profile membership (group membership was dummy coded so that the high aggression and low emotional distress group and the high aggression and declining emotional distress group are compared to the high aggression and moderate-stable emotional distress group).

Joint membership in the high aggressive behavior and high-declining emotional distress trajectory groups accounted for a significant portion of the variance in NOBAGS toward Israeli Jews at Time 3 after controlling for key demographics and normative beliefs at Time $1, \Delta R^{2}=.10, F(7,58)=7.64$, $p<.001$. Youth who simultaneously displayed high aggressive behavior with high-declining emotional distress had significantly higher levels of NOBAGS toward Israeli Jews compared to their peers who displayed high aggressive behavior coupled with moderate emotional distress $(\beta=.26, p<.05)$. There were no significant differences in normative beliefs between members of the high-aggression group with either low or moderate emotional distress (see Table 2).

\section{Discussion}

Although scholarship on risk and resilience has highlighted the dynamic and interrelated nature of adaptation and maladaptation in the context of ethno-political violence, little research has examined these processes as they occur simultaneously and over time. Our findings suggest distinct longitudinal profiles of aggressive behavior and emotional distress under conditions of persistent ethno-political violence, as well as unique patterns of joint membership across both domains. Our findings indicate that youth in key joint profiles are more likely to endorse NOBAGS toward Israeli Jews: Approval of aggression toward Israeli Jews was greatest among Palestinian youth who exhibited both high and stable aggressive behavior with high but declining emotional distress. Overall, this study offers a dynamic perspective on how youth growing up in persistent ethno-political violence adapt emotionally and behaviorally over time, and the implications of those processes.

\section{Trajectories of Aggressive Behavior and Emotional Distress}

Consistent with extant research (Betancourt et al., 2014; Broidy et al., 2003), we found three profiles of aggressive behavior, all of which were stable and varied only by level (low, moderate, high). It is noteworthy that the propensity for aggressive 
Table 2

Regression Analyses Predicting Normative Beliefs About Aggression Toward the Outgroup at Time 3 From High-Stable Aggressive Behavior Groups

\begin{tabular}{lcc}
\hline & Step 1 & Step 2 \\
& $B(S E)$ & $B(S E)$ \\
\hline Age cohort & $-.30(.04)^{* * *}$ & $-.28(.04)^{* *}$ \\
Sex & $.06(.24)$ & $.20(.20)^{*}$ \\
Parents' education & $-.08(.07)$ & $-.06(.07)$ \\
$\quad$ level & $.15(.33)$ & $.05(.48)$ \\
Region & $.55(.11)^{* * *}$ & $.55(.10)^{* * *}$ \\
NBO at T1 & - & $-.18(.24)$ \\
High Agg-Low & - & $.26(.23)^{*}$ \\
ED & & $.10^{* * *}$ \\
High Agg-High & $.42^{* * *}$ & $F(7,58)=7.64$, \\
Dec ED & & $p<.001$ \\
$\Delta R^{2}$ & $F(5,58)=7.55$, & \\
& $p<.001$ & \\
\hline
\end{tabular}

Note Standardized beta coefficients are reported. NBO $=$ normative beliefs about ethnic outgroups; Agg = aggressive behavior; Dec $=$ declining; $\mathrm{ED}=$ emotional distress. ${ }^{\text {a Reference group is }}$ high aggression and moderate emotional distress. $* p \leq .05$. $* * p \leq .01 . * * * p \leq .001$.

behavior does not seem to change across time within individuals, but across level between individuals. These patterns are reasonably consistent with other studies (e.g., Broidy et al., 2003), such that a small but significant group of youth show high and stable aggressive behavior over time. This group is of particular importance because they display problematic adaptation to the violence around them and might need to be targeted for intervention. The majority of youth in the moderate-stable and high-stable aggressive behavior groups were from the West Bank and, consistent with previous research, youth who reported higher levels of aggressive behavior were also more likely to be older and to be male.

Our findings also revealed three emotional distress profiles. First, the low-stable profile represents a group who is consistently emotionally disconnected from ethno-political violence over time. Comparatively, as might be expected under such persistent ethno-political violence, a second group shows moderate-stable levels of emotional distress over time. A third profile, however, represented youth who reported experiencing ethno-political violence as highly distressing (consistent with most findings about exposure to ethno-political violence) followed by significant declines in emotional distress over time. This third profile suggests emotional desensitization, or the gradual decrease in emotional response to traumatic or violent experiences, as youth "adapt" to persistent ethno-political violence around them. The demographic makeup of these emotional distress profiles also offers interesting insight. First, there were no differences in emotional distress group membership based on region. This was in contrast to the regional differences found in aggressive behavior. Such findings may highlight the varying roles that context may play in both internalizing and externalizing processes. Youth in the low-stable emotional distress profile who displayed what might be described as emotional disengagement or detachment tended to be younger, male, and come from families with higher levels of parent education. This finding illustrates that membership in the low-stable emotional distress group may not necessarily reflect emotional detachment, but rather the developmental capacity to understand and internalize exposure to ethno-political violence. It may also reflect gender norms in terms of acceptability of displaying emotional distress. In comparison, youth in the high-declining emotional distress group who displayed what might be described as emotional desensitization, tended to be girls and from families with lower levels of parents' education.

\section{Joint Membership in Aggression-Emotional Distress Trajectory Groups}

When examining joint membership across longitudinal profiles of both aggressive behavior and emotional distress, it is important to note that the majority of youth in our sample displayed adaptation to persistent ethno-political violence by predominantly not having elevated levels of either aggressive behavior or emotional distress over time. This finding supports the assertion that children and youth are resilient (Luthar \& Cicchetti, 2000; Masten, 2014), even in the face of traumatic, toxic, or violent life events such as ethno-political violence. Furthermore, it illustrates that although youth in contexts of ethno-political violence might be at a higher risk for behavioral and emotional issues, it is by no means prescriptive. These findings support literature illustrating the capacity for children and youth to be resilient, giving hope to the assertion that some youth may be able to view reconciliation as feasible in a context of conflict (Ardila-Rey et al., 2009; Posada \& Wainryb, 2008). A small but substantive number of youth, however, were joint members of two key profiles: being highly aggressive while also displaying emotional desensitization over time. These joint trajectories offer new insight into what "positive" or "negative" 
coping means, as the lines between adjustment and maladjustment are blurred in a social ecology filled with violence.

\section{Linking Patterns of Emotional Distress Among High-Aggressive Youth to NOBAGS Toward the Outgroup}

Following theory about the complicated nature of adaptation in contexts of persistent exposure to violence (Boxer \& Sloan-Power, 2013; Luthar \& Cicchetti, 2000; Ng-Mak et al., 2002), we found that endorsement of NOBAGS toward Israeli Jews was greatest among youth who displayed high aggressive behavior coupled with emotional desensitization. These findings indicate that war-related "toxic stress" can lead to a risk of further violence, aggression, and emotional disconnection later in development (Betancourt et al., 2014; Cummings et al., 2010), which has subsequent implications for beliefs about the "other." It also offers support for the existence of varying potential pathways of adjustment, including "pathologic adaptation" (Ng-Mak et al., 2002). From a practical standpoint, this particular group might benefit most from interventions designed to reduce aggression by modifying the social-cognitive and emotional substrates of aggressive responding (Metropolitan Area Child Study Research Group, 2007).

\section{Limitations and Conclusions}

This longitudinal study not only offers a number of important contributions, but also has some key limitations. First, our data are based on youth and parent reports. Although this method allows the opportunity to assess individual perceptions of experience, it may also be limited by the reporters' ability to recall events and their biases in such recollections. Despite this limitation, self-reports are critical for understanding individual perceptions. Second, it might be that exposure to ethno-political violence predicts trajectories of adjustment, subsequently affecting NOBAGS. Future studies should examine these processes across groups who experience varying levels of exposure to ethno-political violence.

Our findings also highlight that one cannot assume homogeneity in the experiences and responses of Palestinian youth to ethno-political violence. Although ethno-political violence has been found generally to impact emotional and behavioral adjustment negatively, studies also have found that many youth growing up in such toxic environments do not necessarily display clinical issues (Barber,
2009; Dubow et al., 2010) and might in fact show incredible resilience (Luthar \& Cicchetti, 2000; Masten, 2014). Future studies should examine simultaneous longitudinal processes of emotional and behavioral adjustment among varying ethnic groups while attending to how those processes are shaped by varying exposure to ethno-political violence, including direct exposure to loss and trauma, over time. Future studies would also benefit from examining how these processes may shape and be shaped by active participation in resistance movements. Although our findings are unique to the Israel-Palestine conflict, they might also be meaningful for any youth who are growing up surrounded by ethno-political violence.

Developmental research has long focused on how risk shapes children's developmental pathways: What is it that places certain youth at risk and, conversely, why do some youth appear resilient in the face of adversity and risk? A concurrent literature on adaptation examines how such risk shapes outcomes. Despite overarching agreement that youth growing up in contexts of adversity are not guaranteed to spiral down a pathway of maladaptation, little research has examined the complex intersecting processes of risk/resilience and adaptation over time among youth who are growing up in contexts of ethno-political conflict. Our findings highlight the dynamic coexistence of risk at the macrolevel and synchrony of developmental pathways across domains at the microlevel. This study takes the critical step of uncovering distinct patterns of emotional and behavioral adjustment over time for a high-risk population of youth, as well as examining the intersections of those processes and their impact on perceptions of the "other." Such work is critical for examining the multifaceted nature of resilience among the millions of youth growing up in a world rife with ethnopolitical conflict.

\section{References}

Achenbach, T., \& Edelbrock, C. (1983). Manual for the child behavior checklist. Burlington, VT: University of Vermont. Allison, P. D. (2001). Missing data. Thousand Oaks, CA: Sage.

Amjad, N., \& Wood, A. M. (2009). Identifying and changing the normative beliefs about aggression which lead young Muslim adults to join extremist anti-Semitic groups in Pakistan. Aggressive Behavior, 35, 514-519. doi:10.1002/ab.20325

Ardila-Rey, A., Killen, M., \& Brenick, A. (2009). Moral reasoning in violent contexts: Displaced and non- 
displaced Colombian children's evaluations of moral transgressions, retaliation, and reconciliation. Social Development, 18, 181-209. doi:10.1111/j.14679507.2008.00483.x

Barber, B. K. (Ed.). (2009). Adolescents and war: How youth deal with political violence. New York, NY: Oxford University Press.

Bar-Tal, D. (2004). The necessity of observing real life situations: Palestinian-Israeli violence as a laboratory for learning about social behavior. European Journal of Social Psychology, 34, 677-701.

Betancourt, T. S., Borisova, I. I., Williams, T. P., Brennan, R. T., Whitfield, T. H., De La Soudiere, M., . . . Gilman, S. E. (2010). Sierra Leone's former child soldiers: A follow-up study of psychosocial adjustment and community reintegration. Child Development, 81, 1077-1095.

Betancourt, T. S., McBain, R. K., \& Brennan, R. T. (2014). Trajectories of externalizing problems among waraffected youth in Sierra Leone: Results from a longitudinal study. Aggression and Violent Behavior, 19, 708-714.

Boxer, P., Huesmann, L. R., Dubow, E. F., Landau, S. F., Gvirmsman, S. D., Shikaki, K., \& Ginges, J. (2013). Exposure to violence across the social ecosystem and the development of aggression: A test of ecological theory in the Israeli-Palestinian conflict. Child Development, 84, 163-177. doi:10.1111/j.1467-8624.2012.01848.x

Boxer, P., \& Sloan-Power, E. (2013). Coping with violence a comprehensive framework and implications for understanding resilience. Trauma, Violence, $\mathcal{E}$ Abuse, 14, 209-221.

Brenick, A., Killen, M., Lee-Kim, J., Fox, N., Leavitt, L., Raviv, A., . . A Al-Smadi, Y. (2010). Social understanding in young Israeli-Jewish, Israeli-Palestinian, Palestinian, and Jordanian children: Moral judgments and stereotypes. Early Education and Development, 21, 886911. doi:10.1080/10409280903236598

Brenick, A., Lee-Kim, J., Killen, M., Fox, N. A., Raviv, A., \& Leavitt, L. A. (2007). Social judgments in Israeli and Arab children: Findings from media-based intervention projects. In D. Lemish \& M. Götz (Eds.), Children and media at times of conflict and war (pp. 287-308). Cresskill, NJ: Hampton Press.

Broidy, L. M., Nagin, D. S., Tremblay, R. E., Bates, J. E., Brame, B., Dodge, K. A., et al. (2003). Developmental trajectories of childhood disruptive behaviors and adolescent delinquency: A six-site, cross-national study. Developmental Psychology, 39, 222-245.

Bronfenbrenner, U. (1979). The ecology of human development. Cambridge, MA: Harvard University Press.

B'Tselem: Israeli Information Center for Human Rights in the Occupied Territories. (2014). Retrieved from http://www. btselem.org//english/statistics/casualties.asp

Cummings, E. M., Merrilees, C. E., Schermerhorn, A. C., Goeke-Morey, M. C., Shirlow, P., \& Cairns, E. (2010). Testing a social ecological model for relations between political violence and child adjustment in Northern Ireland. Development and Psychopathology, 22, 405-418.
Dubow, E. F., Boxer, P., Huesmann, L. R., Landau, S. F., Gvirsman, S. D., Shikaki, K., \& Ginges, J. (2012). Cumulative effects of exposure to violence on post-traumatic stress in Palestinian and Israeli youth. Journal of Clinical Child and Adolescent Psychology, 41, 837-844.

Dubow, E. F., Boxer, L. R., Huesmann, L. R., Shikaki, K., Landau, S., Gvirsman, S., \& Ginges, J. (2010). Exposure to conflict and violence across contexts: Relations to adjustment among Palestinian children. Journal of Clinical Child and Adolescent Psychology, 39, 103-116.

Dubow, E. F., Huesmann, L. R., \& Boxer, P. (2009). A social-cognitive framework for understanding the impact of exposure to persistent ethno-political violence on children's psychosocial adjustment. Clinical Child and Family Psychological Review, 12, 113-126.

Eron, L. D., Walder, L. O., \& Lefkowitz, M. M. (1971). The learning of aggression in children. Boston, MA: Little, Brown.

Finkelhor, D., Turner, H. A., Ormrod, R. K., \& Hamby, S. L. (2010). Trends in childhood violence and abuse exposure: Evidence from two national surveys. Archives of Pediatrics \& Adolescent Medicine, 164, 238-242.

Goodman, R. (2001). Psychometric properties of the strengths and difficulties questionnaire. Journal of the American Academy of Child E Adolescent Psychiatry, 40, 1337-1345.

Goodman, R., Ford, T., Simmons, H., Gatward, R., \& Meltzer, H. (2000). Using the Strengths and Difficulties Questionnaire (SDQ) to screen for child psychiatric disorders in a community sample. The British Journal of Psychiatry, 177, 534-539.

Guerra, N. G., Huesmann, L. R., \& Spindler, A. (2003). Community violence exposure, social cognition, and aggression among urban elementary school children. Child Development, 74, 1561-1576.

Guerra, N. G., \& Huesmann, L. R. (2004). A cognitiveecological model of aggression. International Review of Social Psychology, 17, 177-203.

Huesmann, L. R. (1998). The role of social information processing and cognitive schemas in the acquisition and maintenance of habitual aggressive behavior. In R. G. Geen \& E. Donnerstein (Eds.), Human aggression: Theories, research, and implications for policy (pp. 73-109). New York, NY: Academic Press.

Huesmann, L. R., Eron, L. D., Lefkowitz, M. M., \& Walder, L. O. (1984). Stability of aggression over time and generations. Developmental Psychology, 20, 1120.

Huesmann, L. R., \& Guerra, N. G. (1997). Children's normative beliefs about aggression and aggressive behavior. Journal of Personality and Social Psychology, 72, 408-419.

Jones, B. L., Nagin, D. S., \& Roeder, K. (2001). A SAS procedure based on mixture models for estimating developmental trajectories. Sociological Methods $\mathcal{E}$ Research, 29, 374-393.

Lefkowitz, M. M., Eron, L. D., Walder, L. O., \& Huesmann, L. R. (1977). Growing up to be violent: A longitudinal study of the development of aggression. New York: Pergamon. 
Luthar, S. S., \& Cicchetti, D. (2000). The construct of resilience: Implications for interventions and social policies. Development and Psychopathology, 12, 857-885.

Lynch, M. (2003). Consequences of children's exposure to community violence. Journal of Clinical Child and Adolescent Psychology, 33, 499-505.

Masten, A. S. (2014). Global perspectives on resilience in children and youth. Child Development, 85, 6-20.

Merrilees, C. E., Taylor, L. K., Goeke-Morey, M. C., Shirlow, P., \& Cummings, E. M. (2014). Youth in contexts of political violence: A developmental approach to the study of youth identity and emotional security in their communities. Peace and Conflict: Journal of Peace Psychology, 20, 26.

Metropolitan Area Child Study Research Group. (2007). Changing the way children "think" about aggression: Social cognitive effects of a preventive intervention for early elementary school urban youth. Journal of Consulting and Clinical Psychology, 75, 160-167.

Nagin, D. S. (2005). Group-based modeling of development. Cambridge, MA: Harvard Press.

Nagin, D. S., \& Tremblay, R. E. (2001). Analyzing developmental trajectories of distinct but related behaviors: A group-based method. Psychological Methods, 6, 18-34.

Ng-Mak, D. S., Salziner, S., Feldman, R., \& Stueve, A. (2002). Normalization of violence among innercity youth. American Journal of Orthopsychiatry, 72, 92101.

Niwa, E. Y., et al. (2014). Negative stereotypes of ethnic outgroups: A longitudinal examination among Palestinian, Israeli Jewish, and Israeli Arab youth. Journal of Research on Adolescence, 26(1), 166-179.
Palestinian Central Bureau of Statistics. (2008, August). Census final results in the West bank: Summary (Population and Housing). Ramallah, Author. Retrieved July 7, 2015, from http:// www.pcbs.gov.ps/Portals/_ PCBS/Downloads/book1487.pdf

Posada, R., \& Wainryb, C. (2008). Moral development in a violent society: Colombian children's judgments in the context of survival and revenge. Child Development, 79, 882-898. doi:10.1111/j.1467-8624.2008.01165.x

Schechtman, Z., \& Basheer, O. (2005). Normative beliefs supporting aggression of Arab children in an intergroup conflict. Aggressive Behavior, 4, 324-335.

Schwartz, S. H., \& Struch, N. (1989). Values, stereotypes, and intergroup antagonism. In D. Bar-Tal, C. F. Grauman, A. Kruglanski, \& W. Stroebe (Eds.), Stereotyping and prejudice: Changing conceptions. Berlin, Germany: Springer-Verlag.

UNICEF. (2008). State of the world's children 2008. New York, NY: Author.

Wainryb, C. (2011). 'And so they ordered me to kill a person': Conceptualizing the impacts of child soldiering on the development of moral agency. Human Development, 54, 273-300. doi:10.1159/000331482

Wainryb, C., \& Pasupathi, M. (2010). Political violence and disruptions in the development of moral agency. Child Development Perspectives, 4, 48-54. doi:10.1111/ j.1750-8606.2009.00117.x

Windle, M., \& Weisner, M. (2004). Trajectories of marijuana use from adolescence to young adulthood: Predictors and outcomes. Development and Psychopathology, 16, 1007-1027. 